\title{
O JOGO DE TABULEIRO COMO UMA ESTRATÉGIA AUXILIADORA PARA O ENSINO DE ZOOLOGIA, COM ÊNFASE PARA AS SERPENTES
}

\section{THE BOARD GAME AS A STRATEGY TO HELP THE TEACHING OF ZOOLOGY, WITH EMPHASIS FOR SNAKES}

\author{
Elvis Franklin Fernandes de Carvalho ${ }^{1}$; Petrônio Emanuel Timbó Braga ${ }^{2}$ \\ ${ }^{1}$ Licenciando, Bolsista, PIBID-CAPES. Curso de Ciências Biológicas, \\ Campus da Betânia, Universidade Estadual Vale do Acaraú-UVA, Sobral, Ce. \\ elvis_ffc@hotmail.com \\ ${ }^{2}$ Professor Doutor, Coordenador de área, PIBID-CAPES. Curso de Ciências Biológicas, UVA, Sobral, Ce
}

\begin{abstract}
RESUMO
A utilização do lúdico para dinamizar o aprendizado é um método bastante explorado. O jogo "Na trilha da Serpente", de baixo custo e fácil aplicação, foi elaborado no âmbito do Programa Institucional de Bolsa de Iniciação à Docência (PIBID): Projeto Experiências Inovadoras entre Universidade e Escolas, da CAPES-Coordenação de Aperfeiçoamento de Pessoal de Nível Superior em parceria com a Universidade Estadual Vale do Acaraú-UVA e Secretaria de Educação Básica do Ceará-SEDUC. Foi aplicado a alunos do ensino médio no período de março a maio de 2013 na Escola de Ensino Médio Wilebaldo Aguiar, município de Massapê, Ceará. Para avaliação do jogo, antes e após sua aplicação, aplicaram-se questionários que envolveram questões, dentre outras, sobre a origem, diversidade, sistemática e reprodução das serpentes. Percebeu-se que foi grande o interesse pelos alunos em participar do jogo e que o mesmo aumentou a aquisição de conhecimentos sobre as serpentes.
\end{abstract}

Palavras-Chave: Jogo de tabuleiro, Serpentes, ensino de zoologia.

\begin{abstract}
The use of playfulness to boost learning is a method widely explored. The game "On the trail of the Serpent", of easy implementation, was prepared under the Programa Institucional de Bolsa de Iniciação à Docência (PIBID): Projeto Experiências Inovadoras entre Universidade e Escolas of CAPES 'Coordenação de Aperfeiçoamento de Pessoal de Nível Superior' of Ministry of Education of Brazil in partnership with the 'Universidade Estadual Vale do Acaraú-UVA' and 'Secretaria de Educação Básica do Ceará-SEDUC', having been applied to high school students the period from March to May 2013 in School Wilebaldo Aguiar, municipality of Massapê in State of Ceará. For evaluation of the game, before and after its application, were made questionnaires involved issues about the origin, diversity, systematics and reproduction of snakes. It was great interest in the students to participate in the game and that it increased the acquisition of knowledge about snakes.
\end{abstract}

Keywords: Board game, snakes, teaching zoology. 


\section{INTRODUÇÃO}

O jogo lúdico vem sendo usado amplamente para auxiliar na aprendizagem de discentes, e tem mostrado bons resultados, além disso, tem sido usado para temas não muito abordados em sala de aula de modo a instigar a curiosidade e incentivar a pesquisa pós-sala de aula. Segundo Brancher, Chenet e Oliveira (2005) o lúdico é uma atividade inerente ao ser humano e através da qual pode-se construir uma aprendizagem significativa, onde o educando desenvolve o interesse pelas atividades propostas. Para os mesmos autores, a coletividade na execução dessas, proporciona crescimento intelectual e desenvolvimento físico o que leva a construção da autonomia do ser humano.

De acordo com Alves (2011) o educador é um dinamizador do processo ensinoaprendizagem, em que às vezes encontram-se vertentes ambíguas, mas com dedicação, é possível tornar conteúdos e termos científicos outrora difíceis, confusos em procedimentos prazerosos e interessantes. Um dos métodos que torna isto possível é a utilização de jogos que dinamizem o aprendizado principalmente no ensino médio onde a carga de termos científicos e novas informações relevantes são maiores. Para Detofeno e Justo (2011) um dos grandes anseios dos docentes no ensino médio refere-se à busca de meios para facilitar o processo de aprendizagem, em especial, no ensino de biologia, pois esta disciplina apresenta extensa nomenclatura de termos técnicos, sendo abstrata em alguns conteúdos. Para minimizar o problema, diferentes estratégias podem ser aplicadas, uma delas é o uso de jogos pedagógicos. Assim as aulas tornam-se mais dinâmicas e atraentes, para que os alunos vivam algo novo, para fugir do tradicional esquema de aulas teóricas.

Para Martinez, Fujihara, Martins (2008) o jogo é uma importante ferramenta educacional para auxiliar os processos de ensino-aprendizagem em sala de aula, nos diferentes níveis de ensino e nas diversas áreas do conhecimento. Vários estudiosos ao longo do tempo vêm mostrando os resultados positivos obtidos na utilização de jogos pedagógicos (DETOFENO; JUSTO, 2011). Brancher, Chenet e Oliveira (2005) afirmam que o jogo contribui na melhoria do ensino, na qualificação e também na formação crítica do educando. Além do que essa perspectiva cria possibilidades de diminuir a evasão escolar, haja vista que as práticas lúdicas geram situações de harmonia no ambiente escolar. 
Dentre os jogos utilizados encontramos os do tipo de tabuleiro. Estes exercem fascínio em crianças e adultos (ANTUNES, 1999) e encontramos na literatura alguns trabalhos em que se utilizam o jogo de tabuleiro como ferramenta complementar em algumas áreas, como no ensino de física (PEREIRA; FUSINATO; NEVES, 2009; CARVALHO; CABRAL; CORREA FILHO, 2012; VICTOR; STRIEDER, 2012) e química (LESSA et al., 2010).

$\mathrm{Na}$ área da biologia podem-se mencionar alguns exemplos de atividades lúdicas, com o uso de jogos de tabuleiro com ênfase em temas, como os de botânica (PEREIRA et al., 2009), biotecnologia (ALVES et al., 2008), citologia (ALMEIDA et al., 2008), geologia (CERQUEIRA et al., 2008), meio ambiente (SANTOS et al., 2008a), metabolismo energético (VASCONCELLOS; BONELLI, 2008) e zoologia (ALVES JÚNIOR et al., 2008; CARDOZO et al., 2008; SANTOS et al., 2008b; SANTOS e GUIMARÃES, 2010); CUNHA et al., 2013; PORFÍRIO; MARTINS, 2013).

$\mathrm{Na}$ zoologia, o tema serpentes embora pouco explorado em sala de aula, mas que se faz interessante pelo motivo do misticismo envolvendo as mesmas. O medo que as pessoas têm destes animais os fazem curiosos e ao mesmo tempo torna-os uma ameaça aos mesmos. Com isso um jogo que dinamize o aprendizado sobre serpentes pode fazer com que os alunos percam um pouco do receio com relação estas e aprendam mais sobre as mesmas favorecendo o ensino-aprendizagem sem rejeição por parte do aluno. Também através do jogo pode ser dado início a um trabalho de conscientização para preservação de répteis, pois estes são alvo de mercado ilegal e são mortos muitas vezes sem motivo algum, vítimas do medo e falta de informação da população. Ceuta et al. (2008) desenvolveram o "Jogo das Serpentes", para crianças a partir de 8 anos, com o intuito de conscientizar as pessoas de que as serpentes não são animais vilões, e cujo objetivo do participante era defender uma espécie de cobra brasileira para que ela não entrasse em extinção.

Este trabalho teve como proposta a elaboração e avaliação de um jogo de tabuleiro, na área de zoologia com ênfase no estudo das serpentes, de modo a fazer com que alunos do ensino médio, principalmente, os atendidos pelo Programa Institucional de Bolsa de Iniciação à Docência (PIBID), nas Escolas Dr. João Ribeiro Ramos, em Sobral CE, e Wilebaldo Aguiar, em Massapê, CE, adquirissem mais conhecimento sobre as serpentes. 
Ensino, Saúde e Ambiente - V6 (3), pp. 202-217, dez. 2013

\section{METODOLOGIA}

O presente trabalho foi elaborado no âmbito do Programa Institucional de Bolsa de Iniciação à Docência (PIBID): Projeto Experiências Inovadoras entre Universidade e Escolas, da CAPES-Coordenação de Aperfeiçoamento de Pessoal de Nível Superior em parceria com a Universidade Estadual Vale do Acaraú - UVA e Secretaria de Educação Básica do Ceará-SEDUC, em Sobral, CE, em janeiro de 2013. Desenvolvido e aplicado pelo licenciando durante o período de março a maio do mesmo ano em 3 turmas de $3^{\circ}$ ano na Escola de Ensino Médio Wilebaldo Aguiar, localizada no município de Massapê, Ceará.

O jogo foi confeccionado, manualmente, utilizando materiais de baixo custo e facilmente encontrado no comércio, como papel A4 e denominado de "Na Trilha da Serpente". Constou de um tabuleiro de papel formado por quatro folhas de papel A4 40 $\mathrm{kg}$ medindo no total $58 \mathrm{~cm}$ x $42 \mathrm{~cm}$, dado e pinos marcadores de plástico, para marcar as casas, neste caso foi utilizado peças de bijuteria. A imagem do tabuleiro foi confeccionada utilizando-se figuras retiradas da internet e com o auxílio dos softwares Microsoft Word, Paint e finalizada o programa Photoscape. Depois de finalizada, a imagem foi dividida em quatro partes e estas foram impressas no papel $40 \mathrm{~kg}$ e coladas formando o tabuleiro (Figura 1).

Para jogar, inicialmente, é necessário lançar o dado e avançar o número de casas correspondente ao número sorteado, ao chegar à determinada casa o aluno deve ler o enunciado ou observar a figura, o número de jogadores pode variar de dois a quatro. É importante o acompanhamento do professor ou monitor para esclarecimento de possíveis dúvidas. Há alguns questionamentos durante o jogo que os alunos participantes deverão responder o que instiga a discussão do assunto entre os mesmos. Será considerado vencedor o participante que chegar primeiro ao final das casas do jogo. Ressalta-se que pode jogar mais de uma vez, aumentando assim a possibilidade de absorver mais informações sobre as serpentes. 
Figura 1. Ilustração do tabuleiro do jogo "Na trilha da Serpente".

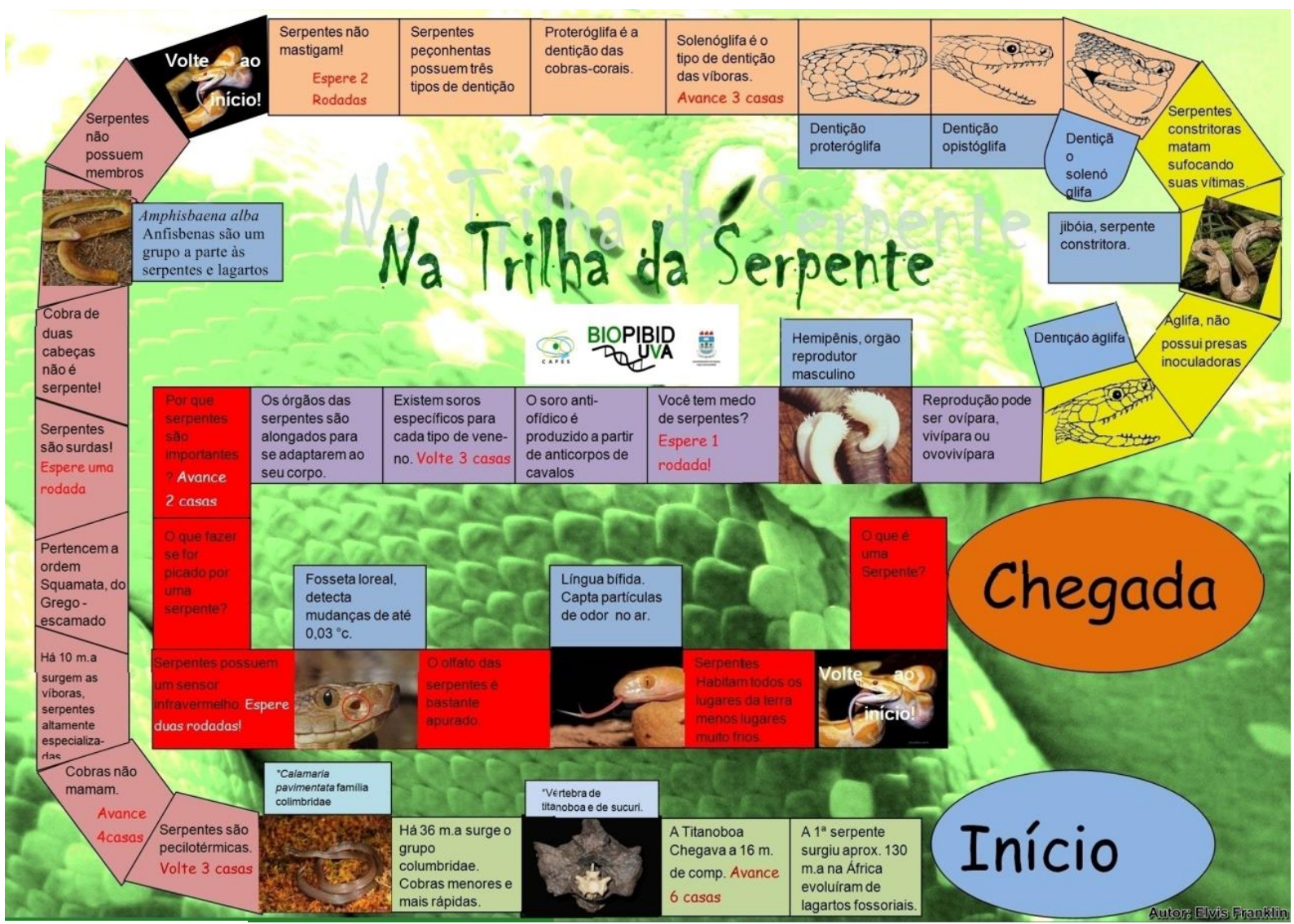

Fonte: $\mathrm{O} 1^{\mathrm{o}}$ autor.

Para avaliar os conhecimentos prévios dos alunos aplicou-se um questionário em horário convencional de aulas, antes de ser comentado qualquer assunto sobe o jogo a 40 alunos, no que foi chamado de pré-teste. Posteriormente, foi aplicado um questionário idêntico, ou seja, com as mesmas questões sobre conhecimentos específicos do conteúdo das serpentes logo após a aplicação do jogo, então denominado pós-teste, para que fosse possível verificar e quantificar os conhecimentos prévios. A aplicação destes questionários constituiu-se no parâmetro de comparação antes e após a realização do jogo. Ressalta-se que em razão do $2^{\circ}$ ano do ensino médio ser estudado os seres vivos, onde se inclui o estudo das serpentes, foram escolhidas as turmas de $3^{\circ}$ ano, pois estes já teriam um conhecimento prévio sobre as mesmas.

O questionário aplicado foi composto por oito questões de múltipla escolha, onde apenas uma era correta e algumas com a opção "não sei” e outras bem específicas com apenas "sim" ou "não" como alternativas com intuito de avaliar os conhecimentos prévios dos alunos, sejam populares ou científicos. As questões envolviam temas como a origem, diversidade, sistemática e reprodução das serpentes assim como aspectos ISSN 1983-7011 
ligados a saúde como conhecimentos sobre soro antiofídico e como proceder diante de uma picada de serpente.

A análise dos dados foi feita pela comparação dos dados do pré e pós-teste. Segundo Santos e Guimarães (2010) a análise da eficiência de jogos educativos no ensino de zoologia pode ser demonstrada a partir da avaliação do pré e pós-teste. E, para digitalização dos dados da pesquisa fez o uso do software Microsoft Excel, onde foi realizada a tabulação dos dados e elaborados gráficos. Foram então os dados obtidos analisados por intermédio de procedimentos da estatística descritiva, através do cálculo das freqüências relativas das respostas dadas, sendo os resultados apresentados em porcentagens.

\section{RESULTADOS E DISCUSSÕES}

Para a realização da atividade da aplicação a sala foi dividia em equipes de quatro pessoas, onde cada equipe ficou com um tabuleiro e cada aluno ficou com uma peça marcadora do jogo. Neste momento, foi importante o acompanhamento do professor ou monitor para esclarecer possíveis dúvidas.

A desvantagem de um jogo de tabuleiro é que há uma probabilidade de que nem todas as casas possam ser observadas. Segundo Lopes (2013) como o jogo utiliza dado, então o fator sorte não pode ser totalmente desprezado. Porém, no jogo "Na Trilha da Serpente" o intuito principal é a informação e o aprendizado, logo, esta situação é facilmente contornada se após a atividade, o professor esclarecer as dúvidas dos alunos sobre o jogo e analisá-lo por completo, sendo uma tarefa simples, pois o jogo não é muito extenso no que pode, ainda, ser jogado várias vezes em uma hora/aula.

Para avaliar a eficiência do jogo "Na trilha da Serpente" como auxílio à prática de ensino, questões que versavam sobre serpentes foram aplicadas antes e depois do jogo. A primeira questão apresentada tratou do conhecimento da fosseta loreal, um órgão que representa um sistema termo receptor muito bem desenvolvido (GUIMARÃES, 2008). O conhecimento deste órgão pode ser utilizado para identificar serpentes da família das víboras que são peçonhentas. Segundo Sebben (1996) é possível identificar uma cobra venenosa através da fosseta loreal, que é um orifício que fica entre os olhos e as narinas e que serve como sensor de calor, com exceção da cobra coral que não possui a fosseta loreal. Dos entrevistados, apenas $25 \%$ afirmaram saber a 
função deste órgão, entretanto, após a aplicação do jogo $100 \%$ afirmaram conhecê-lo (Figura 2).

Figura 2. Média das respostas dadas pelos estudantes à questão que versava sobre o conhecimento da fosseta loreal, referentes aos questionários pré-teste e pós-teste.

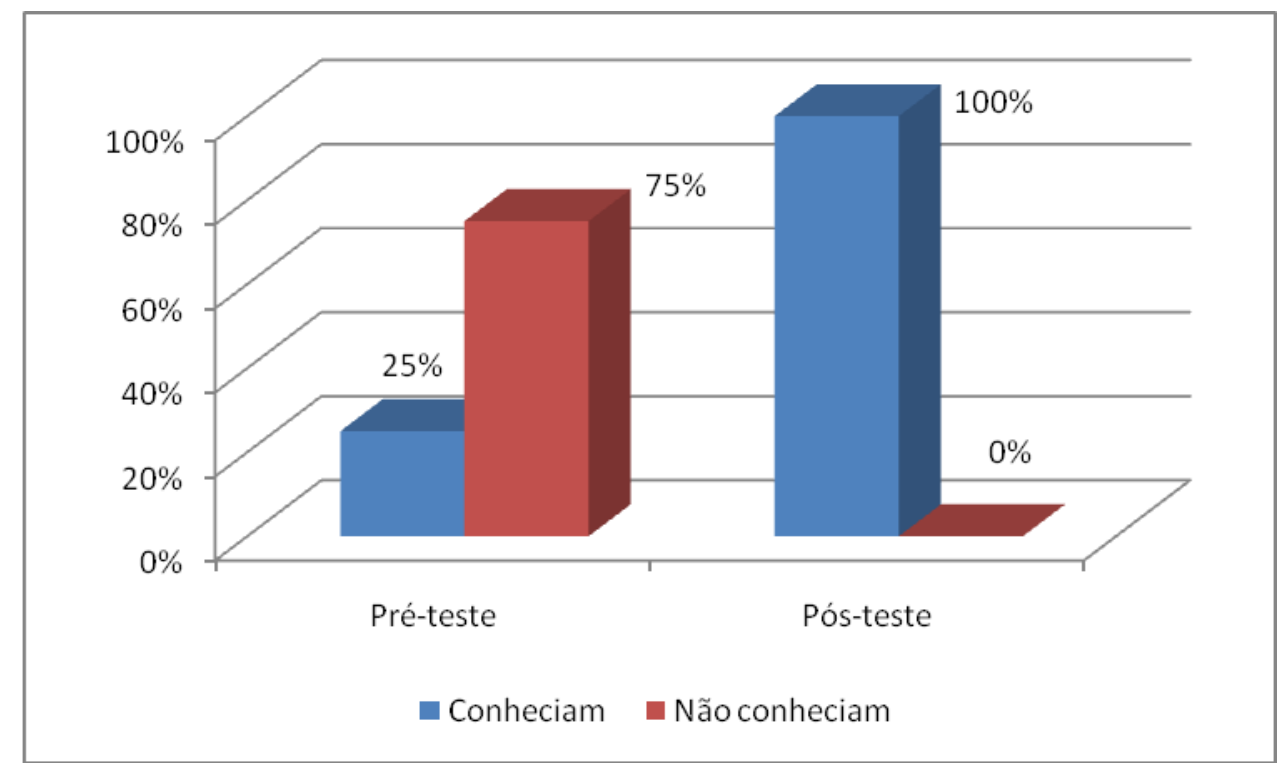

Fonte: $\mathrm{O} 1^{\mathrm{o}}$ autor.

Sobre o conhecimento da reprodução, com ênfase ao órgão reprodutor (hemipênis) que apresenta grande quantidade de características como forma $\mathrm{e}$ ornamentação, características estas que vêm sendo utilizadas como fonte de informação para estudos em sistemática e taxonomia (NUNES, 2011), observou-se serem estas desconhecidas pelos estudantes, onde, apenas $15 \%$ dos entrevistados, afirmaram conhecer o órgão reprodutor antes da aplicação do jogo e $80 \%$ afirmaram conhecer após a aplicação (Figura 3). 
Figura 3. Média das respostas dadas pelos estudantes à questão que versa sobre o conhecimento do órgão reprodutor referentes aos questionários pré-teste e pós-teste.

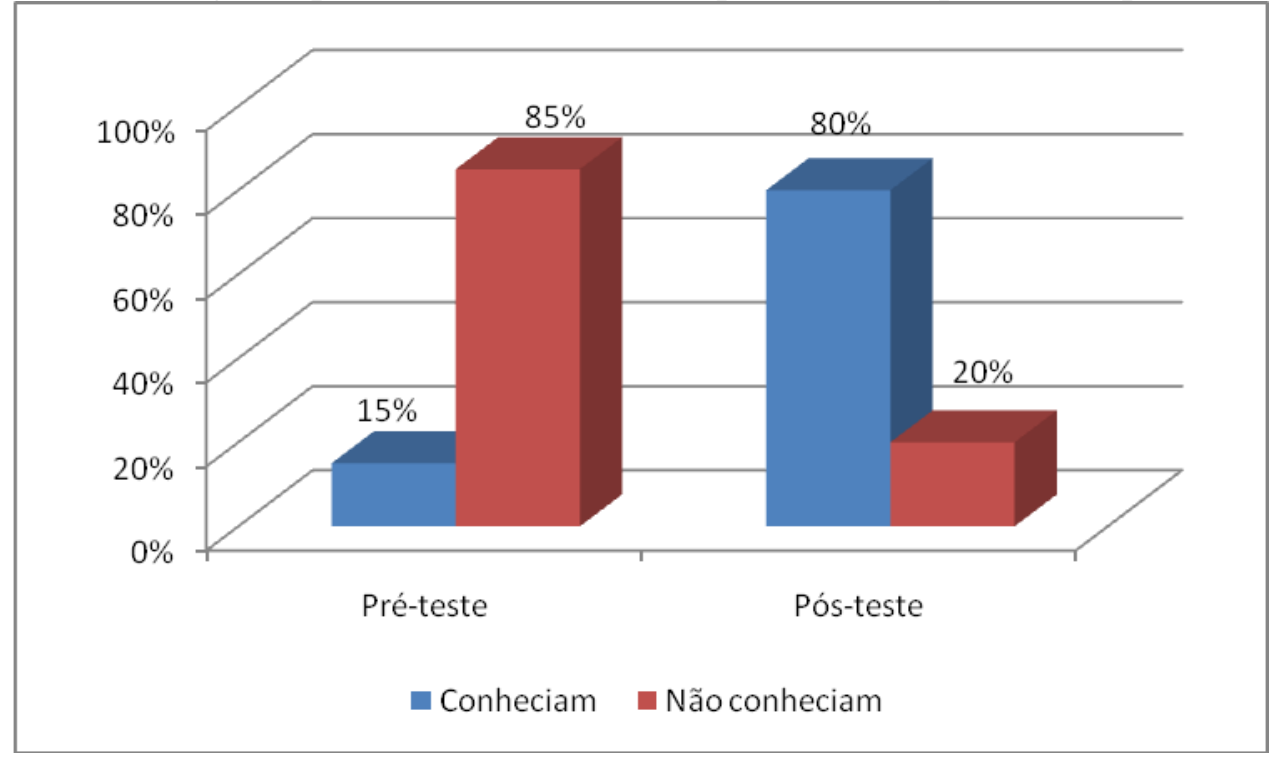

Fonte: $\mathrm{O} 1^{\mathrm{o}}$ autor.

No que diz respeito à dentição das serpentes, onde segundo Mosmann (2001) é um fator de grande importância para alimentação e identificação destes animais, ao serem questionados sobre quantos tipos de formação dentária existiam, apenas, $20 \%$ dos estudantes entrevistados responderam corretamente no pré-teste, entretanto, após a aplicação do jogo, este índice aumentou para 80\% (Figura 4).

Figura 4. Média das respostas dadas pelos estudantes à questão que versa sobre o conhecimento sobre os tipos de formação dentárias das serpentes referentes aos questionários pré-teste e pós-teste.

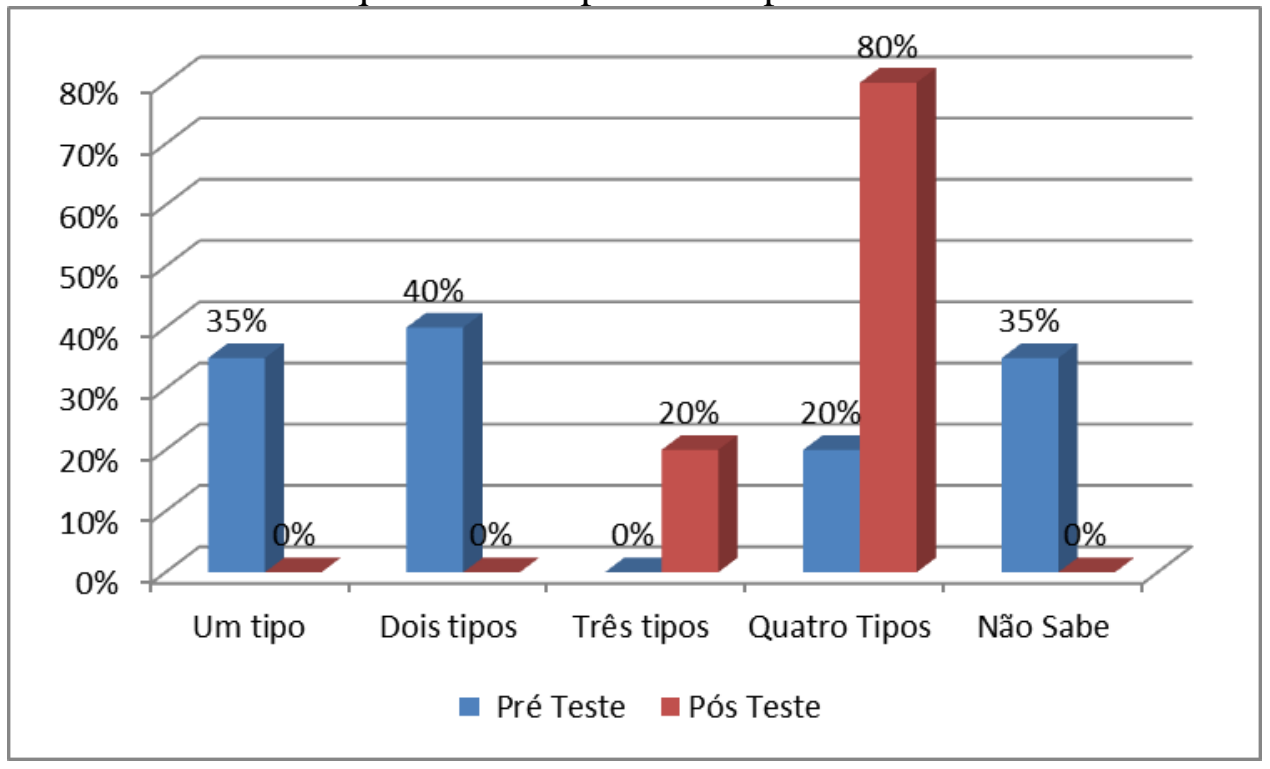

Fonte: $\mathrm{O} 1^{\mathrm{o}}$ autor. 
No que diz respeito ao mito popular de serpentes possuírem a capacidade de mamar, sabe-se que não há serpentes que possuam o hábito de ingerir leite. Além de não fazer parte da dieta, o exercício de sucção seria impossível, devido à ausência do músculo esfíncter bucal (FERNANDES-FERREIRA et.al, 2011). Todavia, 61\% dos estudantes afirmaram que as serpentes possuem a capacidade de mamar, 35\% afirmaram que elas não têm esta característica e 4\% não souberam afirmar (Figura 5).

Figura 5. Média das respostas dadas pelos estudantes à questão que versava sobre o conhecimento sobre o mito de que as serpentes possuem a capacidade de mamar.

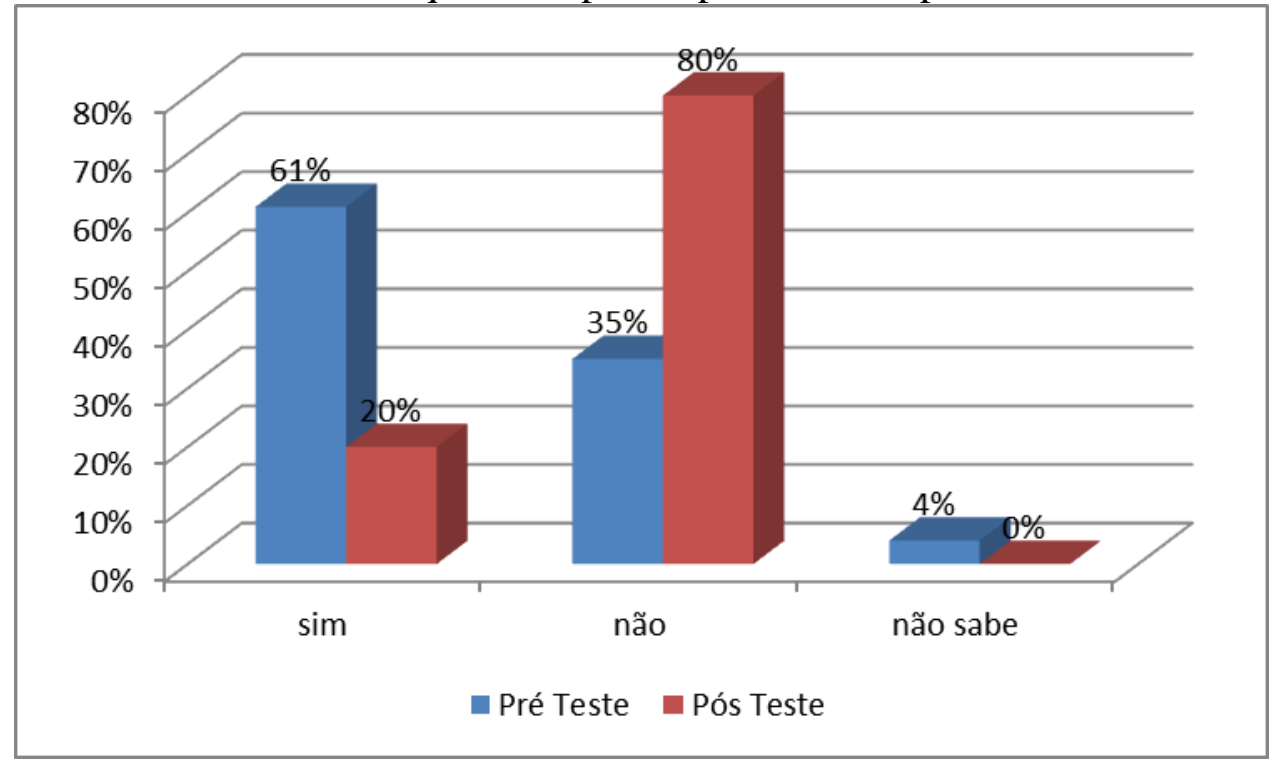

Fonte: $\mathrm{O} 1^{\mathrm{o}}$ autor.

Outra questão versou sobre o nascimento dos filhotes de serpentes. Durante muito tempo, classificaram-se os modos reprodutivos das serpentes em: ovíparo (para as que depositam os ovos no ambiente), ovovivíparo (para as que retêm os ovos, com casca, no útero e depois parem filhotes já formados) e vivíparo (para as que parem filhotes sem a formação de ovos com casca no útero). Entretanto, viviparidade (do latim, vivus pario) significa parir vivo. Desta forma, o termo ovovivíparo caiu em desuso e estabeleceu-se que oviparidade implica na postura de ovos com casca, contendo embriões relativamente pouco desenvolvidos, ao passo que viviparidade caracteriza-se pelo parto do filhote totalmente formado, independente da retenção de ovos no útero (ovo-retenção) (SHINE, 1985 apud PIZATTO; ALMEIDA-FRANCO; MARQUES, 2006). Dos entrevistados, $75 \%$ afirmaram que os filhotes nascem apenas 
por oviparidade, entretanto, após a aplicação do jogo este número caiu para 5\% (Figura $6)$.

Figura 6. Média das respostas dadas pelos estudantes à questão que versava sobre o conhecimento evolvendo as formas de nascimento dos filhotes de serpentes.

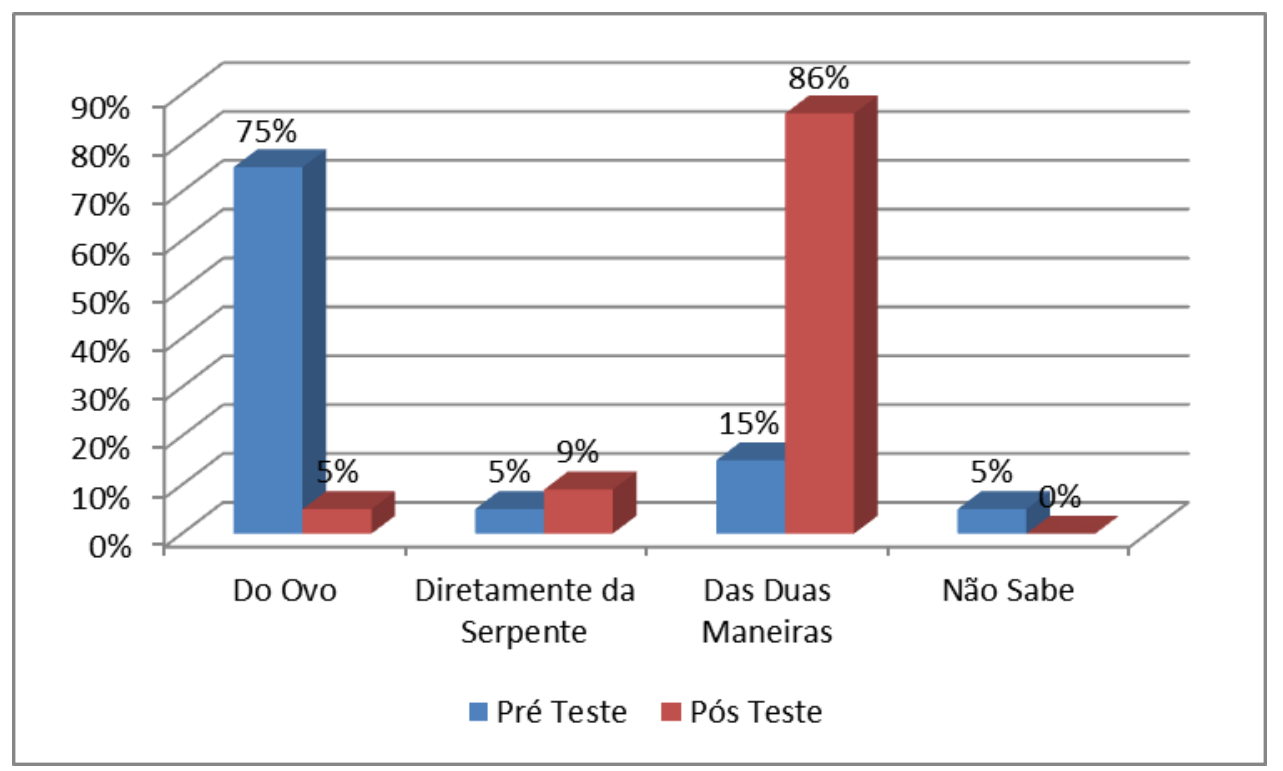

Fonte: $\mathrm{O} 1^{\mathrm{o}}$ autor.

Foi questionado aos estudantes conhecimentos sobre a anfisbena que frequentemente é confundida com serpente. Popularmente conhecidos como "cobras-deduas-cabeças", os anfisbenídeos constituem um grupo de répteis de hábitos estritamente fossoriais (habitam galerias no solo que constro-em com o próprio corpo). Juntamente com as serpentes e os lagartos, formam o grupo Squamata (répteis portadores de escamas que sofrem mudas periódicas chamadas ecdises) (VALVERDE; OLIVEIRA, 2011). Para Rodrigues (2005) e Baptista et al. (2008) citados por Mateus et al. (2011) os Amphisbaenia são geralmente confundidos com serpentes, e mortos em razão da antipatia e do medo que despertam nas pessoas.

Segundo Pough, Janis e Heiser (2003) citados por Mateus et al. (2011) o nome popular "cobra-de-duas-cabeças" é atribuído aos anfisbenídeos pelo fato de apresentarem a cabeça e a cauda semelhantes morfologicamente, correspondendo a uma adaptação ao hábito escavador e à vida subterrânea. Sobre a questão, $70 \%$ dos estudantes afirmaram que a anfisbena seria serpente e $15 \%$ acreditavam ser este organismo, um anfíbio ou lagarto. Após a aplicação do jogo, o percentual de acerto foi 
76\%, ou seja, a maioria dos estudantes entrevistados acreditava ser nem serpente ou anfíbio (Figura 7).

Figura 7. Média das respostas dadas pelos estudantes à questão que versava sobre os conhecimentos da anfisbena ou cobra-de-duas-cabeças.

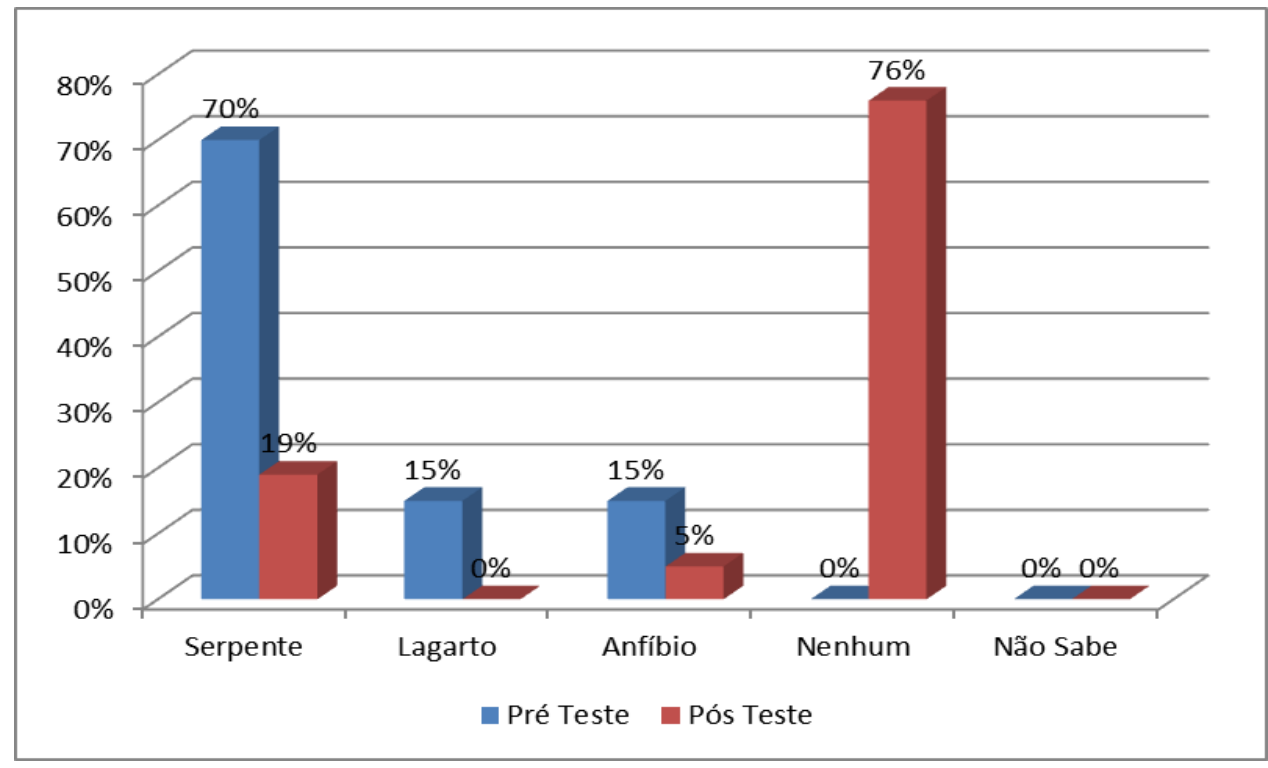

Fonte: $\mathrm{O} 1^{\mathrm{o}}$ autor.

Abordou-se sobre a origem do material o qual é produzido o soro antiofídico, no caso em um processo denominado hiperimunizacão onde o veneno da serpente é diluído e injetado no cavalo, em doses adequadas para após ser recolhido em um processo chamado sangria, então é centrifugado retirado os anticorpos que serão utilizados para a fabricação do soro (INSTITUTO BUTANTAN, 2006). Sobre esta, na fase da aplicação do pré-jogo, observou-se que $85 \%$ dos estudantes afirmaram ser a partir do veneno da serpente. Após o jogo, $80 \%$ dos entrevistados afirmaram ser o soro antiofídico produzido a partir de anticorpos de cavalos (Figura 8).

Sobre o conhecimento de como proceder diante de uma picada de serpente, observou-se que antes da aplicação do jogo cerca de $10 \%$ dos estudantes entrevistados acreditavam que chupar o local da picada seria o procedimento mais eficiente (Figura 9), o que na realidade é um procedimento inadequado devido ao risco de proliferação bacteriana no ferimento (FERNANDES-FERREIRA et al., 2011). 
Figura 8. Média das respostas dadas pelos estudantes à questão que versava sobre a matéria prima para a produção do soro antiofídico.

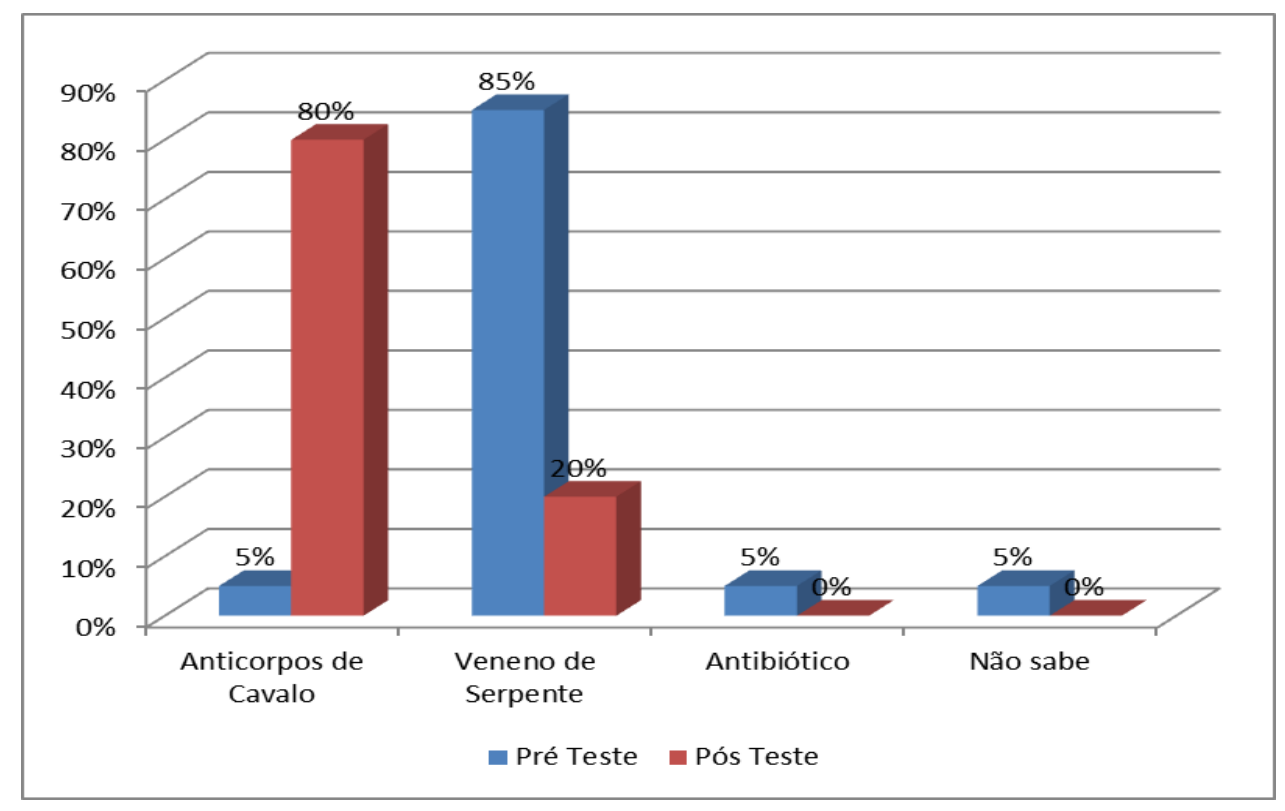

Fonte: $\mathrm{O} 1^{\mathrm{o}}$ autor.

Figura 9. Média das respostas dadas pelos estudantes à questão que versava sobre o procedimento mais seguro a ser tomado a uma picada de serpente.

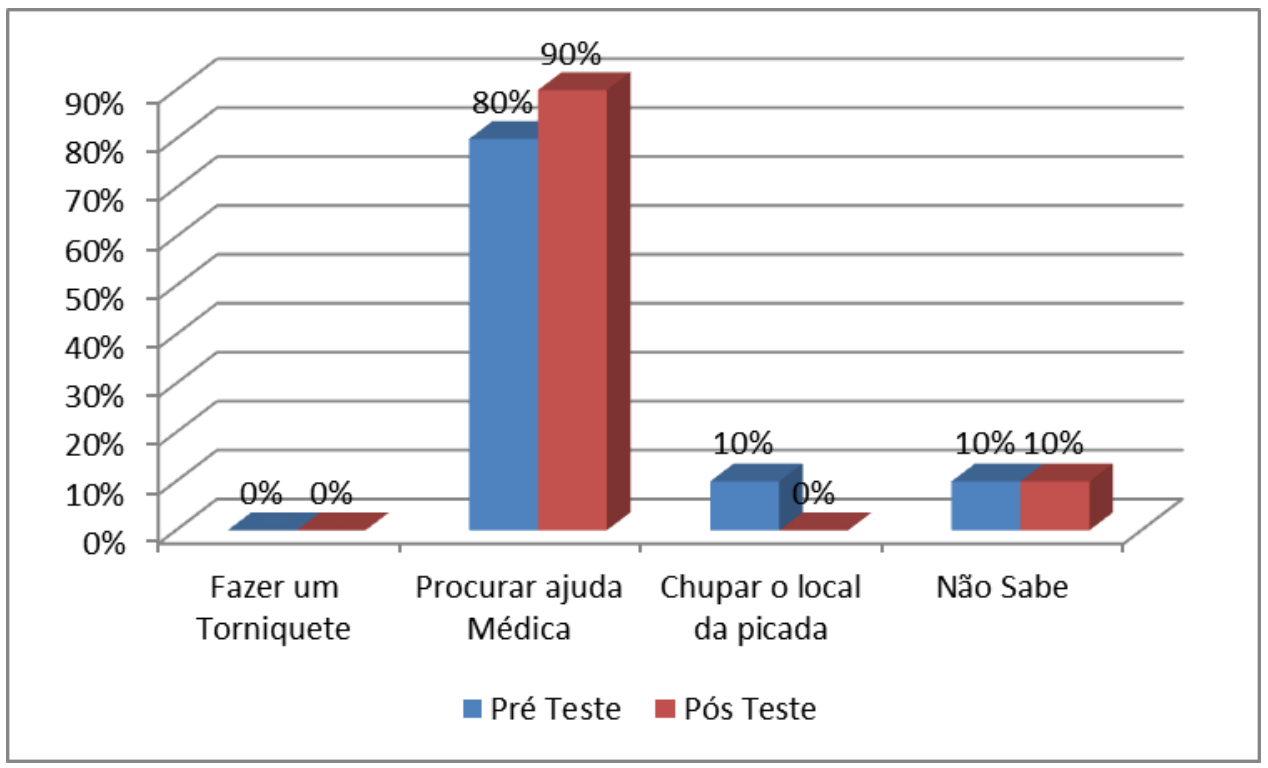

Fonte: $\mathrm{O} 1^{\mathrm{o}}$ autor.

\section{CONSIDERAÇÕES FINAIS}

Percebeu-se que foi grande o interesse pelos alunos em participar do jogo e que o mesmo aumentou a aquisição de conhecimentos sobre as serpentes. Foi percebível, 
ainda, a desvantagem do jogo de tabuleiro cujas respostas a algumas perguntas estavam explícitas no jogo e não foram respondidas de forma correta, pois as casas do jogo onde se encontravam não foram devidamente visualizadas.

Todavia, após o jogo quando os estudantes haviam manifestados suas dúvidas estas foram esclarecidas. Também mitos foram esclarecidos como os exemplifados de que serpentes mamavam em seios de seres humanos ou de que serpentes hipnotizavam suas vítimas humanas. Ainda, com a aplicação do jogo criou-se um clima agradável e interessante que despertou a curiosidade dos estudantes e coube ao professor iniciar um trabalho de conscientização para preservação dos répteis. Por tudo isso, reforça-se a ideia de que os jogos lúdicos serem uma boa opção para sair da rotina monótona da sala de aula sem prejudicar o aprendizado.

Portanto, o jogo didático intitulado "Na Trilha da Serpente", de baixo custo e fácil aplicação, pode ser usado para reforçar ou fixar sobre o conhecimento das serpentes visto em sala de aula. Cumpre, assim, um importante papel em despertar o interesse dos estudantes por animais, ainda, pouco estudados e desmistificar lendas populares que os prejudicam, podendo levá-los até mesmo a extinção, tudo isso em meio a um ambiente descontraído no que estimula também a comunicação entre os alunos.

\section{REFERÊNCIAS BIBLIOGRÁFICAS}

ALMEIDA, C. H. C.; BATISTA NETO, R. P; MISE, Y. F; ARAÚJO, L. G.; PINTO, O. A. S. Show do Celulão. In: Ciência Lúdica: Brincando e Aprendendo com Jogos sobre Ciências/Rejâne Maria Lirada-Silva (Organizadora). Salvador: Universitária da UFBA, EDUFBA, 204p., 2008. p. 163-165.

ALVES JÚNIOR, F. T.; PINTO, O. A. S.; MISE, Y. F.; SILVA, R. M. L. A. In:

Ciência Lúdica: Brincando e Aprendendo com Jogos sobre Ciências/Rejâne Maria Lirada-Silva (Organizadora). Salvador: Editora Universitária da UFBA, EDUFBA, 204 p., 2008. p. 27-32.

ALVES, P. A.; NUNES, J. V; TELES JÚNIOR, J. B; MISE, Y. F; SANTOS, E. P; ARAÚJO, L. G. Biotec. In: Ciência Lúdica: Brincando e Aprendendo com Jogos sobre Ciências/Rejâne Maria Lirada-Silva (Org.). Salvador: Editora Universitária da UFBA, EDUFBA, 204 p., 2008 (p. 41-43).

ALVES, R. J. L. O lúdico no ensino de citologia e sua importância para o desenvolvimento de competências e habilidades. 2011. Monografia (Licenciatura em Ciências Biológicas). Consórcio Setentrional de Educação a Distância, Universidade de Brasília/UEG, Brasília, 2011. 43p. 
ANTUNES, C. Jogos para a estimulação das múltiplas inteligências. $11^{\text {a }}$ ed. Petrópolis: Editora Vozes, 1999.

BRANCHER, R. V; CHENET, N; FORTES, O. V. O lúdico na aprendizagem infantil. Revista do Centro de Educação, n. 27. 2005. Disponível em: <http://coralx.ufsm.br/revce/ ceesp/2006/01/r10.htm>. Acesso em: 18 jan. 2013.

CARDOZO, R. X. C; PEREIRA, L. A. C; TELES JUNIOR, J. B; MISE, Y. F; SANTOS, E. P; ARAÚJO, L. G. Beijo da morte. In: Ciência Lúdica: Brincando e Aprendendo com Jogos sobre Ciências/Rejâne Maria Lirada-Silva (Organizadora). Salvador: Editora Universitária da UFBA, EDUFBA, 204 p., 2008. p. 131-134.

CARVALHO, C. M.; CABRAL, J. R. R.; CORRÊA FILHO, J. A. O lúdico no ensino de física: um jogo de tabuleiro como recurso metodógico. 2012. Disponível em: <http://www.ufsj.edu.br/portal2-repositorio/File/pibidfisica/Trabalhos\%20Divulgados/ II\%20Seminario\%20PIBID/Cristiane_Marina_et_al.pdf > Acesso em: Acesso em: 15 mai. 2013.

CERQUEIRA, H. J.; SANTOS, M. C. O.; FRANÇA, C. A. S.; RIBEIRO, H. L.; DORES, J. L. R.; FRANÇA, L. R. F.; ARAÚJO, L. G.; SANTOS, B. P. S. Zoogeografia: brincando com as teorias evolucionistas. In: Ciência Lúdica: Brincando e Aprendendo com Jogos sobre Ciências/Rejâne Maria Lirada-Silva (Organizadora). Salvador: Editora Universitária da UFBA, EDUFBA, 204 p., 2008 p. 189-192.

CEUTA, M.; SANTANA, V.L.; ANDRADE, A.O.; MISE, Y.F.; SILVA, R.L.S; MARQUES, R.S.; SILVA, I.A.O. Jogo das Serpentes. Em: Em: Ciência Lúdica: Brincando e Aprendendo com Jogos sobre Ciências/Rejâne Maria Lirada-Silva (Organizadora). Salvador: Editora Universitária da UFBA, EDUFBA, 204 p., 2008 (p. 121-123).

CUNHA, E.V.; MATOS, E.P.N.B.; SOUZA, O.M.; RIBEIRO, L.V.; BATALHA, J.R. Tabuleiro dos crustáceos: compreendendo as características deste grupo de animais invertebrados, através de um jogo. In: Encontro de Zoologia do Nordeste (17: 2013: Maceió, AL) Livro de resumos e programa oficial (Organ. Tereza Cristina dos Santos Calado e Wagner José dos Santos). Maceió: Universidade Federal de Alagoas, Sociedade Nordestitina de Zoologia, 2013. p. 543

DETOFENO, A. M.; JUSTO, C.F. Jogos pedagógicos: uma alternativa para os professores e um anseio dos alunos. Interdisciplinar: Revista Eletrônica da Univar, n. 7 p. 129-134, 2011.

FERNANDES-FERREIRA, H.; CRUZ, R. L.; BORGES-NOJOSA, D. M.; ALVES, R. R. N. Crenças associadas a serpentes no estado do Ceará, Nordeste do Brasil.

Sitientibus série Ciências Biológicas, v.11, n. 2, p.153-163. 2011.

GUIMARÃES B. Serpentes, Escorpiões \& Aranhas: identificação, prevenção e tratamento. ESPE, Estudo e Pesquisa Ed. 2008. 11p. 
INSTITUTO BUTANTAN. Soros e Vacinas. Série didática Número 2. Disponível em : <http://www.butantan.gov.br/home/pdfs/material_didatico/2/numero2.pdf> Acesso em 31. jul. 2013

LESSA, M. D.; CRESPO, L. C.; PEÇANHA, R. M.; GIACOMINI, R. A. Jogo de tabuleiro para o ensino de química no ensino médio: repensando a dinâmica da sala de aula. In: II Congresso Fluminense de Iniciação Científica e Tecnológica. 2010. Disponível em: <http://www.essentiaeditora.iff.edu.br/index.php/confict/article/view/ 2578.> Acesso em: 15 mai. 2013.

LOPES, J. M. O Estudo da Concepção Clássica de Probabilidade Através Do Jogo Mini-Bozó. Encontro Nacional de Educação Matemática. 2013 Disponível em <http://sbem.bruc.com.br/XIENEM/pdf/670_69_ID.pdf> Acesso em: 31. jul. 2013

MARTINEZ, E. R. M.; FUJIHARA, R. T.; MARTINS, C. Show da Genética: um jogo interativo para o ensino de genética. Genética na Escola, 2008. Disponível em: $<$ http://www.diaadiaeducacao.pr.gov.br/diaadia/diadia/arquivos/File/conteudo/artigos_t eses/Biologia/Artigos/showgene.pdf>. Acesso em: 15 mai. 2013.

MATEUS, M. B.; PINTO, L. C. L.; MOURA, M. R.; PIRES, M. R. S. A cobra-de-duascabeças na percepção dos moradores do povoado de Itatiaia, Minas Gerais. Biotemas, v. 24, n.3, p.111-117, 2011.

MOSMANN, M. N. Guias das Principais Serpentes do Mundo. Canoas: ed. Ulbra. 2001.38p.

NUNES, P. M. S. Morfologia hemipeniana dos Lagartos Microteídeos e suas Implicações nas Relações Filogenéticas da Família Gymnophthalmidae (Teiioidae: Squamata) Tese (Doutorado) Instituto de Biociências da Universidade de São Paulo. Departamento de Zoologia. 2011.

PEREIRA, R. F; FUSINATO, P. A.; NEVES, M. C. D. Desenvolvendo um jogo de tabuleiro para o ensino de física. In: VII Encontro Nacional de Pesquisa em educação em Ciências, Florianópolis. p. 12-23, 2009. Disponível em: <http://posgrad.fae.ufmg.br/posgrad/viienpec/pdfs/1033.pdf > Acesso em: 15 mai. 2013.

PEREIRA, T. C. A.; PAES, L. S.; MELLO, M. S. V. N.; FERREIRA, M. V.; ZACKSON, R. R. Estratégias para ensino de botânica com jogos de tabuleiro. IV Congresso de Pesquisa e Inovação a Rede Norte e Nordeste de Educação Tecnológica. Belém, Pa, 2009. Disponível em:< http://connepi2009.ifpa.edu.br/connepianais/artigos/191_3018_1979.pdf> Acesso em: 15 mai. 2013.

PIZZATTO, L.; ALMEIDA-SANTOS, S. M.; MARQUES, O. A. V. Biologia reprodutiva de serpentes brasileiras. In: Herpetologia no Brasil. P. 201-221. 2006. Disponível em: $<$ http://ligiaoceanica.byethost9.com/Herpetologia\%20no\%20Brasil.pdf $>$ Acesso em: 17 jul. 2013.

PORFÍRIO, T.A.; MARTINS, F.P.S. Procurando os artrópodes: um jogo para auxiliar o ensino aprendizagem do Filo Arthropoda. In: Encontro de Zoologia do 
Nordeste (17: 2013: Maceió, AL) Livro de resumos e programa oficial (Organ. Tereza Cristina dos Santos Calado e Wagner José dos Santos) - Maceió: Universidade Federal de Alagoas, Sociedade Nordestitina de Zoologia, 2013. p. 537.

SANTOS, A. B.; GUIMARÃES, C. R. P. A utilização de jogos como recurso didático no ensino de zoologia. Revista Electrónica de Investigación en Educación en Ciencias, v. 5, n. 2, p.52-57, 2010.

SANTOS, C. C.; SILVA, F.; SANTOS, L. V. J.; SILVA, R. L.; PAMPONET, B. Morte Silenciosa. In: Ciência Lúdica: Brincando e Aprendendo com Jogos sobre Ciências/Rejâne Maria Lirada-Silva (Organizadora). Salvador: Editora Universitária da UFBA, EDUFBA, 204p., 2008, p. 125-126.

SANTOS, I. D.; ARAUJO, B. R. N. ; CERDEIRA, I. M. G.; PINTO, O. A. S. Combatendo a Extinção. In: Ciência Lúdica: Brincando e Aprendendo com Jogos sobre Ciências/Rejâne Maria Lirada-Silva (Organizadora). Salvador: Editora Universitária da UFBA, EDUFBA, 204p., 2008. p. 63-65.

SEBBEN, A. Cartilha de Ofidismo. Editora Universidade de Brasília, Brasília: 1996. VALVERDE, M. C. C.: OLIVEIRA, M. J. M. Amphisbaenia: Conhecer para preservar. Universidade Estadual de Feira de Santana, 2011. Disponível em: <http://www2.uefs.br/dcbio/arquivos/folder\%20anfisbenia.pdf.>. Acesso em: 21 jul. 2013.

VASCONCELLOS, L. C.; BONELLI, R. R. Desenvolvimento de um jogo de tabuleiro destinado a aumentar o nível de aprendizado e interesse do aluno pelo metabolismo energético no ensino médio. In: XII Encontro Latino Americano de Iniciação Científica e VIII Encontro Latino Americano de Pós-Graduação Universidade do Vale do Paraíba. p.1-4, 2008. disponível em: <http://www.inicepg.univap.br/cd/INIC_2008/anais/arquivosINIC/INIC1368_01_O.pdf. Acesso em: 14 mai. 2013.

VICTOR, R. A.; STRIEDER, R. B. Atividades lúdicas e ensino de astronomia: uma Proposta envolvendo jogo de tabuleiro. 2012. Disponível em: <www.ucb.br/sites/100/118/TCC/2²012/TCCRaquelAraujoVictor.pdf. > Acesso em: 14 mai. 2013. 